\title{
Literatura de tradición oral en La Higuerilla de Tejeda, Islas Canarias
}

\section{Orally Transmitted Literature in La Higuerilla de Tejeda, Canary Islands}

\author{
Andrés Monroy Caballero \\ (Universidad de Las Palmas de Gran Canaria) \\ andres.monroy@ulpgc.es \\ ORCID ID: 0000-0002-8944-485X
}

\begin{abstract}
This article faithfully depicts the oral tradition of La Higuerilla, in the rural area of Tejeda (Gran Canaria), within the Canary Islands. The reporter, María del Socorro García Quintana and her two daughters, provide us with an important collection of romances, songs (the arrorró nursery rhyme, coplas and other folk songs), tales and stories of witches, aberruntos, and candil and children's dance games The genre best represented is that of the coplas and tales of witches, as well as a good collection of romances. The corpus that the reporter owns is faithful to a part of the tradition that existed in the past, but which is now very difficult to recover.
\end{abstract}

KEYWORDS: Orally transmitted literature, Canary Islands, Tejeda, Gran Canaria
RESUMEN: El presente artículo refleja fielmente la tradición oral de La Higuerilla, núcleo rural de Tejeda (Gran Canaria) en las Islas Canarias. La informante, María del Socorro García Quintana y sus dos hijas, nos aportan un conjunto importante de romances, cantares (el arroró para dormir a los niños, coplas y otras canciones populares), cuentos e historias de brujas, aberruntos y juegos de bailes de candil e infantiles. El género mejor representado es el de las coplas y la historias de brujas, además de una buena colección de romances. El legado que posee la informante es fiel a una parte de la tradición que existió en el pasado, pero que ya es muy difícil de recuperar.

PALABRAS-CLAVE: Literatura de tradición oral, Islas Canarias, Tejeda, Gran Canaria

La literatura de tradición oral en Canarias, muy viva hasta hace pocas décadas y actualmente en riesgo de desaparición en algunas de sus modalidades, es muy rica y variada en cuanto a subgéneros. Desde los romances, los estribillos romancescos, los cantares, el punto cubano, los Aires de Lima, los Ranchos de Ánimas y de Pascua, las leyendas y cuentos tradicionales, hasta el teatro popular; en Canarias podemos encontrar toda la gama de posibilidades que existen en la Península. Unos muy vivos actualmente, como el canto del romancero a través del baile del tambor de La Gomera, y otros perdidos definitivamente de la tradición oral canaria. De ahí la necesidad de rescatar estas manifestaciones orales en los lugares más aislados, donde mejor vive la tradición, de los aires del olvido que asolan frenéticamente este nuevo mundo de la globalización y de las nuevas tecnologías que destruyen las costumbres en pos de una visión monolítica, igualitaria y repetitiva de la sociedad actual por todo el planeta.

Un ejemplo de la tradición oral canaria es el que nos aporta la transmisora María del Socorro García Quintana, de 74 años, más conocida como Socorrito, nacida en la 
localidad de La Higuerilla en Tejeda, perteneciente a la isla de Gran Canaria (Islas Canarias). Esta mujer, actualmente residente en Casa Pastores (Santa Lucía de Tirajana, Gran Canaria), nunca ha sido entrevistada y prácticamente no sabe leer ni escribir. Fue encuestada en febrero y junio de 2017 y en noviembre de 2018, junto a sus hijas Esther y Teresa.
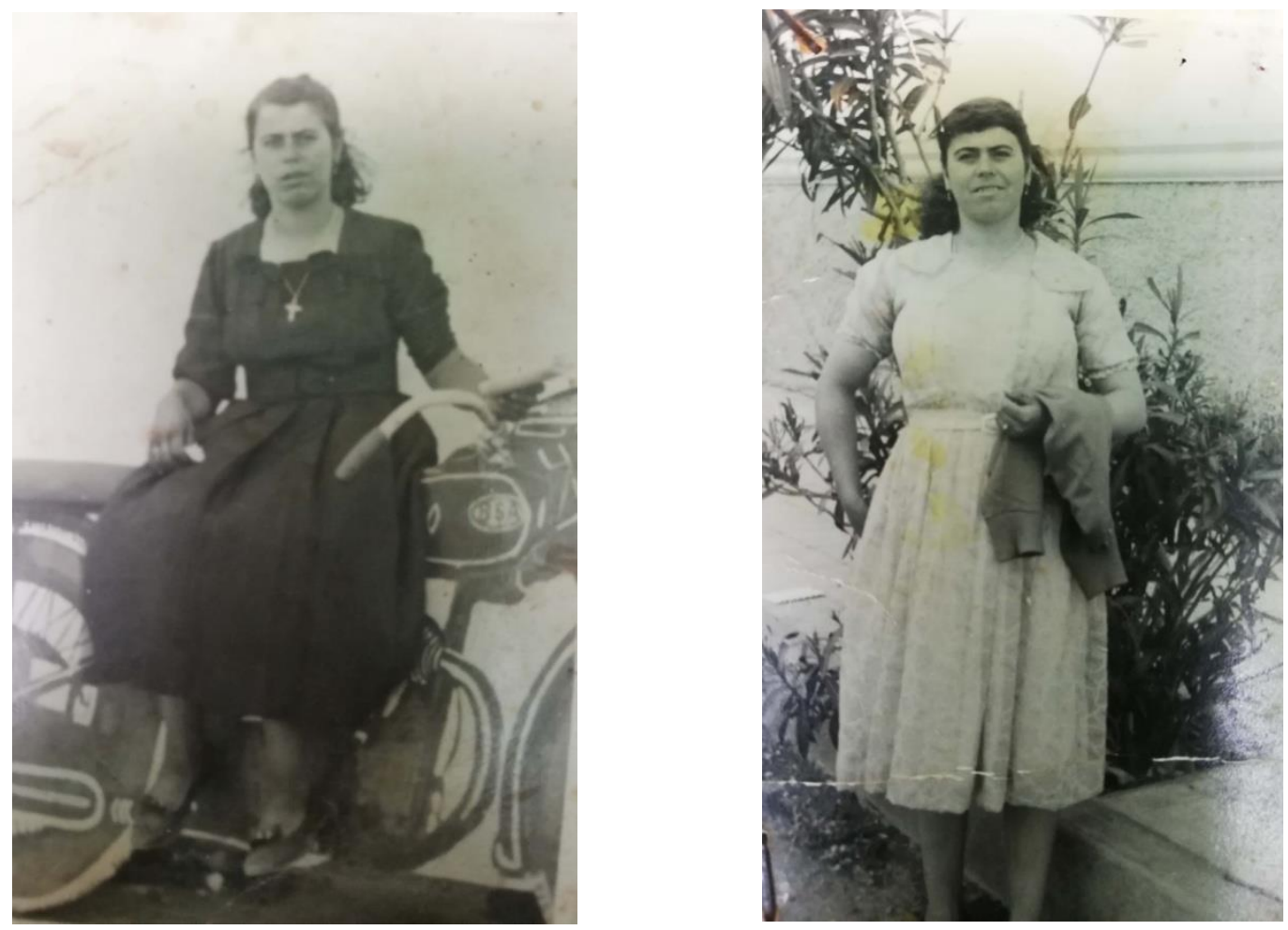

Ella cuenta que vivió en Tejeda hasta los 19 años aproximadamente, residiendo posteriormente en las Cuarterías de Calderín cerca del Tablero de Maspalomas cinco años, y que luego se fue a vivir a Casa Pastores hace 52 años. Pero los primeros 19 años de su vida los pasó bebiendo de la tradición de Tejeda gracias al legado tradicional que le transmitió su madre, y sobre todo, su padre a los que define como personas muy alegres. «Mi padre me enseñó un cantar», dice Socorrito, porque muchos de los textos que aparecen a continuación los conoce de oírselo a él. Y con los cantares se divertían y pasaban el tiempo, hacían bailes entre amigas porque no les permitían ir a fiestas ya que poco más tenían: un vestido nuevo para salir, unos zapapitos... y poco más. Lo de Socorrito y su familia era trabajar para poder subsistir con los pocos recursos con los que se contaba entonces.

Esos cantos tenían lugar en los momentos de ocio y también durante el trabajo. Ella nos dice que ha trabajado cuidando cabras, vacas y otros animales; además de cultivar la tierra: arar, surcar, echar estiércol, etc. y de tareas relacionadas con la agricultura: coger piñas, coger almendras, coger monte, coger hierba,... Cultivó la zanahoria, trabajó en la zafra del tomate y lo último que hizo fue trabajar en el empaquetado del tomate en el almacén con Pepito Nicolás. Dice Socorrito:

Yo tenía ocho años y tenía ocho cabras. Mi hermana guardaba siete y yo ocho.

Pero buscábamos almendras, y almendros dulces, si por casualidad nos hallábamos 
dos almendras una para ti y otra para mí, y si nos hallábamos tres almendras una para ti y otra para mí y la otra la partíamos.

Mi padre decía sobre robar: «Ustedes cojan con los codos todo lo que puedan», y como no se puede coger nada con los codos...

Íbamos a la junta a partir almendras, a descamisar piñas, desgranar millo, ir a trillar, recoger sementeras, etc. Se trillaba con las vacas, dentando, seillando los chícharos, la cebada, la lenteja, centeno... Había que trabajar. En esos tramos había muchos cantares bonitos pero ya no me acuerdo, y mi padre era un hombre que nos enseñaba mucho.

También nos habla de otras personas que conocían la tradición, como su hermana Juana, y familiares, ya muchos de ellos tristemente desaparecidos.

Cuando no consignamos el dato del informante, nos referimos a María del Socorro García Quintana, puesto que la recolección aportada es esencialmente de esta informante.

\section{ROMANCERO}

Del romancero canario, Socorrito nos ha aportado siete romances, el primero es un romance catalogado por Maximiano Trapero de «tradicional de amor fiel» (2000: 154158), como es El quintado:

Ya viene marzo y abril, ya viene la primavera, ahí vienen los soldados que van para la guerra.

Unos cantan y otros lloran, y otros se mueren de pena;

el soldadito más chico iba como una magdalena

$5 \quad$ ¿Por qué llora, soldadito?

¿Llora por padre o por madre o por morirse en la guerra?

-Ni lloro por padre, ni lloro por madre ni por morirse en la guerra:

lloro por una hermanita que dejé en mi casa enferma.

De este romance, se han recogido en Canarias 25 versiones: 5 versiones en $\mathrm{La}$ Palma (Trapero, 2000b: 154-157), 6 versiones en Tenerife (Catalán, 1969a, I: 278-279, 347-349), 3 versiones en Gran Canaria (Trapero, 1990a: 133-135), 3 versiones en Gran Canaria (Trapero, 1982a: 203-204), 3 versiones en Fuerteventura (Trapero, 1991: 58-59), 1 versión en Lanzarote (Trapero, 2003a: 101), 1 versión en Tenerife (Hernández Díaz, 1988: 99-100), 1 versión en Tenerife (Hernández González, 1989: 33-34), 2 versiones en Gran Canaria (Tarajano, 2004: 197, 223). Junto a ellas, encontramos contaminaciones: $E l$ quintado + Atropellado por el tren con 1 versión en Tenerife (Catalán, 1969a, I: 279); El quintado + La aparición de la enamorada muerta + La hermana cautiva con 1 versión en Gran Canaria (Trapero, 1990a: 139); y El quintado + La aparición de la enamorada muerta con 16 versiones, siendo estas 2 versiones en La Palma (Trapero, 2000b: 158), 2 versiones en El Hierro (Trapero, 1985a: 186-187), 4 versiones en La Gomera (Trapero, 2000a: 335-337), 6 versiones en Gran Canaria (Trapero, 1990a: 135-138), 2 versiones en Lanzarote (Trapero, 2003a: 102-103).

Dentro del apartado de romances religiosos tenemos El discípulo amado, precedido por Las tres Marías:

Jueves santo a mediodía Jesucristo caminaba con una cruz en sus hombros de madera muy pesada. Allá en el monte Calvario tres Marías le lloraban: una, la Virgen pura; otra, la Magdalena; 
y otra Marta, su hermana, la más dolor que pasaba.

Una le lava sus pies; otra, su bendita cara;

y otra barre su sangre que Jesucristo derramaba.

Quien la sabe, no la dice;

quien la oye, no la aprende;

10

el día del juicio sabrá;

y quien la gana, la pierde.

Socorrito nos cuenta que este texto lo cantaban cuando iban a misa. Curiosamente, al ser un rezado, no se cantaba en Canarias. Pero nos dice nuestra transmisora que: «nosotros los cantábamos un ranchao ${ }^{1}$ de chiquillas, de camino el jueves y el viernes santos, las grandes y las chicas juntas». Se trata de un romance religioso muy común en Canarias y con muchas contaminaciones, como podemos comprobar en las versiones recogidas de El discípulo amado (Muerte de don Alonso de Aguilar, a lo divino) de las que contamos 6 versiones: 1 versión en La Palma (Trapero, 2000b: 361-362), 2 versiones en El Hierro (Trapero, 2006: 213-214), 1 versión en La Gomera (Trapero, 2000a: 371), 1 versión en Gran Canaria (Trapero, 1990a: 368-369), 1 versión en Fuerteventura (Trapero, 1991: 128). A ello hay que añadir las contaminaciones como: El discípulo amado $+E l$ monumento de Cristo con 1 versión en La Gomera (Trapero, 2000a: 373-374); El discípulo amado + La sangre de Cristo con 2 versiones en Gran Canaria (Tarajano, 2004: 41, 200); El discípulo amado + Las tres Marías + La sangre de Cristo con 2 versiones: 1 versión en Gran Canaria (Trapero, 1982a: 416), 1 versión en Gran Canaria (Tarajano, 2004: 63); El discípulo amado + Las tres Marías + La Virgen camino del Calvario con 3 versiones: 1 versión en Tenerife (Catalán, 1969a, I: 205-206), 1 versión en Gran Canaria (Trapero, 1982a: 415), 1 versión en Tenerife (Pérez Rodríguez, 1981: 205); El discípulo amado + Las tres Marías + Las mujeres de Jerusalén con 1 versión en Gran Canaria (Trapero, 1982a: 417); El discípulo amado + Las tres Marías + Llanto en el monte Calvario y otros motivos sacros varios con 1 versión en Tenerife (Catalán, 1969a, I: 296); El discípulo amado + Las tres Marías con 6 versiones: 1 versión en La Gomera (Trapero, 2000a: 372-373), 2 versiones en Tenerife (Catalán, 1969a, 204-205), 1 versión en Gran Canaria (Trapero, 1990a: 369), 2 versiones en Lanzarote (Trapero, 2003a: 195-196); El discípulo amado + Rezados varios con. 1 versión en La Gomera (Trapero, 2000a: 374); y El discípulo amado + Santa Catalina con 1 versión en La Gomera (Trapero, 2000a: 371372).

Otro romance religioso que conoce la transmisora es el de Acto de Contrición, catalogado por Trapero en el subgrupo de «Rezados y devotos»:

Señor mío Jesucristo, de su nombre verdadero, no murió por los pecados, que murió por los ajenos.

En la Cruz está colgado con fuertes clavos de hierro.

¡Madre mía de mis ojos, madre mía, mi cordero!;

5 y la tierra que yo piso, ¡madre mía, la merezco!

..................... a este rosario le ofrezco

no tengo nada que darle

Madre, sumiso,

a la Gloria, amén.

10 Me cago en la madre que lo parió, un creo, Señor.

\footnotetext{
${ }^{1}$ Grupo de niñas.
} 
Dice Socorrito que: «Mi padre me ensañaba eso, y mi madre, los dos [textos anteriores]». En total, podemos encontrar 23 versiones Canarias: 1 versión en La Palma (Trapero, 2000b: 390), 8 versiones en Gran Canaria (Trapero, 1990a: 403-405), 1 versión en Gran Canaria (Trapero, 1982a: 403), 5 versiones en Fuerteventura (Trapero, 1991: 140142), 3 versiones en Lanzarote (Trapero, 2003a: 205-207), 1 versión en Tenerife (Pérez Rodríguez, 1981: 202), 4 versiones en La Palma (Hernández, 2006: 88-90); y varias contaminaciones como: Acto de contrición + La Virgen camino del Calvario + Soledad de la Virgen con 1 versión en Gran Canaria (Trapero, 1982a: 403) y Acto de contrición + Los presagios del labrador con 1 versión en La Gomera (Trapero, 2000a: 382).

La siguiente composición pertenece a los romances vulgares modernos popularizados sobre «la conquista amorosa» y lleva por título De quince años yo tuve un novio:

De quince años yo tuve un novio, que lo quería más que al vivir; mi madre me dijo un día que lo tenía que despedir.

Una mañana muy tempranito a la ventana yo me asomé, le hice señas con el pañuelo cogí la ropa y me fui con él.

$5 \quad$ Llegó la noche............. pidiendo posada para los dos aquella noche una viejita $\quad . . \ldots \ldots \ldots \ldots \ldots \ldots$........ buscando un cuarto para los dos

- ¡Ay, Manolo mío, Manolo de mi corazón!

Tu primera carta me cayó en la acera,

10 la segunda, en mi corazón donde Manolo me enamoró.

Salimos de mi ventana, salimos juntos los dos.

la tercera me enamoró.

Ese otro día salimos juntos buscando un cuarto para los dos.

15 Quisiera tener un niño,

con tu misma vacuna. ¡Manolo mío!, te quiero yo.

Se trata de un romance recogido solo en Gran Canaria, como lo demuestra las 6 versiones de De quince años yo tuve un novio recogidas: 5 versiones en Gran Canaria (Trapero, 1982a: 385-386), 1 versión en Gran Canaria (Tarajano, 2004: 88).

Otro romance vulgar moderno popularizado, de temática sobre «amores estorbados, malogrados y desgraciados», es el de La Agustinita:

En la calle Siete Iglesias se ha muerto una jovencita, hija de Antonio Jiménez, que la llaman Agustinita:

- iAy, padre, que mala estoy! ¡Ay, madre, me voy a morir!, mande a buscar a mi novio, que me quiero despedir.-

$5 \quad$ Y el padre le contesta con palabras muy resueltas:

- iEnque ${ }^{2}$ te mueras mil veces tu novio no entra en la puerta!

- ¡Vaya padre malo tengo! ¡Vaya familia tirana,

que antes de morir su hija están haciendo la caja!

Y la caja era de oro y la tapa de madera,

10 que se la hizo el tirano para que Julio la viera.

Cuando Julio se enteró que Agustina era muerta,

se monta en su borriquillo hasta llegar a la puerta.

\footnotetext{
${ }^{2}$ Aunque.
} 
- ¡Adiós, mi novia Agustina, la de los ojitos negros,

la que me ha dejao pasar varios ratitos de sueños!-

15 El entierro día alante, sus hermanos por los lados,

y su padre día atrás fumándose el tabaco.

Este romance, cantado por María del Socorro, de La Agustinita (Agustinita y Redondo) ha sido recogido en 7 versiones en Canarias: 1 versión en La Palma (Trapero, 2000b: 524), 5 versiones en Gran Canaria (Trapero, 1982a: 286-288), 1 versión en Lanzarote (Trapero, 2003a: 217).

También dentro del subgénero de los romances vulgares modernos popularizados, de temática sobre la «historia contemporánea», tenemos a Marianita Pineda:

Marianita salió de su casa al encuentro salió el militar.

- iSi don Pedro me viera bordando la bandera de la libertad!-

La bandera que estaba bordando era blanca, azul y encarná, al centro un letrero que dice: «Vaya para Cuba, mamá».

5 - Mamá, recoge a mis hijitos que voy a La Habana a fallar.-

Bastante con su sangre los alimentó

- ¡Ay Marianita, hermosa, Marianita de mi corazón!

El romance, cantado por María del Socorro, remite a la conocida historia de Mariana de Pineda Muñoz, ejecutada el 26 de mayo de 1831 durante el reinado de Fernando VII por bordar, como dice el romance, una bandera liberal. En total, se han recolectado 20 versiones del romance en las Islas Canarias: 6 versiones en La Palma (Trapero, 2000b: 497-498), 6 versiones en Gran Canaria (Trapero, 1990a: 431-435), 5 versiones en Gran Canaria (Trapero, 1982a: 310-312), 1 versión en Fuerteventura (Trapero, 1991: 264), 1 versión en Gran Canaria (García López, 2005: 103), 1 versión en Gran Canaria (Tarajano, 2004: 90).

Finalmente, el último texto recogido de Socorrito es el romance local Duelo entre amigos:

Entre Ingenio y Agüimes, de noche en la Candelaria, en un juego de turrón dos hombres se desafiaban.

Juan Pérez, como era hombre, y su fuerza le ayudaba

las piedritas del camino le servían de alumbrada.

$5 \quad$ Entre el medio ${ }^{3}$ del camino a su madre se encontraba:

- ¿Qué tienes, hijo Juan Pérez? ¿Qué tienes, hijo del alma?

-Que me ha matado un hombre que Juan Valentín se llama.

Madre, si se lo encuentra por el camino, madre, no le diga nada

porque yo tuve la culpa que el muchacho me matara.

10 Adiós, mi cabrita rusia ${ }^{4}$, adiós, mi vaca galana.

ya no tienes quien te dé las vueltas que yo te daba,

por la mañana en la umbría y de tarde en la solana,

al peso del mediodía en la fuente de agua clara;

ya no tienes quien te lleve de noche en la Candelaria.

Un romance de creación local de probable carácter verídico sobre una disputa entre dos personas en Gran Canaria que, curiosamente, también ha sido recogido en

\footnotetext{
3 'En el medio'.

${ }^{4}$ Se refiere al color del animal, «rucia», con el seseo propio de Canarias.
} 
Lanzarote y Fuerteventura como podemos comprobar en las 28 versiones de este romance de Duelo entre amigos: 17 versiones en Gran Canaria (Trapero, 1990a: 559-659), 8 versiones en Gran Canaria (Trapero, 1982a: 247-250), 1 versión en Fuerteventura (Trapero, 1991: 272-273), 1 versión en Lanzarote (Trapero, 2003a: 275), 1 versión en Gran Canaria (Tarajano, 2004: 183-184). En opinión de Maximiano Trapero, la fecha de composición de este romance pudo haber sido antes de 1819, puesto que Ingenio aún era un barrio del Ayuntamiento de Agüimes (Trapero, 1989: 209-210). Pero la única noción temporal que da es la del día de la Candelaria.

En cambio, a la pregunta de si se acordaba de los ciegos que vendían pliegos con romances por las calles María del Socorro García Quintana nos dice que no recuerda verlos, posiblemente porque su localidad de la infancia no fuera muy transitada a causa de la lejanía y lo abrupto del lugar, puesto que se encuentra en el centro de Gran Canaria entre altas montañas.

\section{CANCIONERO}

En Canarias, a las canciones que se cantan a los bebés o nanas se les conoce como arrorós, y este tipo de textos son muy comunes en el archipiélago. Pérez Vidal, comentado en extenso en su obra Folclore infantil canario (1986: 29-77), Maximiano Trapero en su obra Lírica Tradicional Canaria (1990b: 59-65) y Luis Diego en El folklore infantil y otros estudios etnográficos (1991: 33-36) han publicado varias versiones de arrorós. Por su parte, María del Socorro García Quintana ha aportado el siguiente texto:

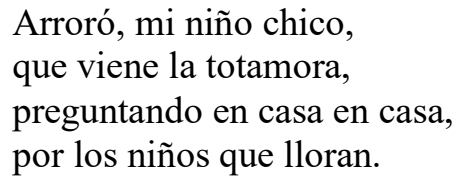

El arroró es un canto para dormir a los niños, y lo curioso es que en el mismo canto utilice expresiones para asustarlos si no se duermen. Si el niño entendiera la letra de la composición, no dormiría. Según la transmisora, «la totamora es una mora», y el sentido de la letra es 'si no duermes viene la mora y te lleva'. Curiosamente, la palabra totamora no aparece recogido en el Tesoro Lexicográfico del Español de Canarias (TLEC); ni en el Diccionario de Canarismos (DC) de Lorenzo, Morera y Ortega; como tampoco en el Diccionario Básico de Canarismos (DBC) de la Academia Canaria de la Lengua ni en el Diccionario de la Lengua Española (DRAE) ${ }^{5}$ de la Real Academia Española. Además, este texto era cantado de la siguiente forma:
Arrorró, mi niño chico
que viene la totamora
preguntando de casa en casa
al ver los niños que llora,
al ver los niños que llora.
Ahí viene la totamora.

En cuanto al género del cancionero más numeroso presente en el repertorio de María del Socorro, la copla es el que más destaca y el más significativo por cuanto casi todas las composiciones que presentamos a continuación son totalmente inéditas en el

\footnotetext{
${ }^{5}$ A partir de ahora se utilizarán las siglas especificadas.
} 
repertorio canario porque estamos ante creaciones muy locales en la geografía insular. E1 orden seguido en este apartado es el de la transmisión, tal cual nos lo ha contado y en función de su mayor facilidad para recordar. Además, nos dice Socorrito, que la copla tiene «cuatro palabras» en la acepción de palabra como 'versos' propia de Canarias (no recogida ni en el $T L E C$, en el $D C$, en el $D B C$, ni en el $D R A E$ ), y que muchas de ellas se cantaban en los momentos de ocio o durante el trabajo cogiendo higos, almendras, etc. Incluso se decían en picardía entre los jóvenes. Reseñamos las otras publicaciones de las coplas únicamente en los casos en que exista, puesto que la mayor parte de ellas aquí relacionadas son inéditas. Para ello, las obras consultadas han sido: Caleidoscopio de coplas palmeras (1993) de Felipe Santiago Fernández Castillo, Lírica Tradicional Canaria (1990b) de Maximiano Trapero, Folklore infantil canario y otros estudios etnográficos (1991) de Luis Diego Cuscoy, Folclore infantil canario (1986) y Poesía tradicional Canaria (1968) de José Pérez Vidal, La música tradicional, hoy (1998) de Talio Noda Gómez. La primera de ellas es muy propia de la tradición oral, la mención a lugares de Gran Canaria conocidos por los recitadores o cantores y sus correspondientes santos patronos:
Por san Juan voy a Artenara, por san Nicolás a la Aldea, por san Antonio a Mogán, por Socorro a Tejeda.

De estos cantares, nos dice Socorrito, sabe un montón. En realidad, para la transmisora, serían cantares de «seis palabras», porque al cantarlos repetían algunos versos, como ocurre en la siguiente copla:
Las estrellitas del cielo caminan todas de lado. Las estrellitas del cielo caminan todas de lado; así está mi corazón siempre por ti sesperado ${ }^{6}$.

La temática habitual es la amorosa, en donde los astros como el sol, la luna, las estrellas, la aurora y la naturaleza entera cobran protagonismo como personajes vivos dentro del imaginario de la lírica tradicional. Así, la aurora como señora que nos abriga con su manto y el cielo con la cualidad humana de vestirse, junto con la aparición del letrero como representación de lo escrito y la fijación en los ojos de la amada que alumbra más que un cartel de neón, son referidas en la siguiente cuarteta:

Cuando la aurora tiende su manto

el cielo santo viste de azul,

no hay letrero que alumbre tanto

como los ojos que tienes tú.

La anómala agrupación en esta copla de dos preposiciones «de sobre», con la intención de elevar el nivel sociolingüístico hacia una visión de más prestigio de lo

\footnotetext{
6 'Desesperado'.
} 
hablado y de dar solemnidad a la imagen del corazón encima de una laja, una piedra grande y plana, se basa en las alusiones constantes a la naturaleza (piedra y sol):

De sobre esta lajita ${ }^{7}$

te dejo mi corazón.

¡Alevántate temprano

desde la salida del sol!

Nos comenta María del Socorro que lo cantaban los chiquillos y chiquillas, de serenatas, para divertirse.

La comparación de la naturaleza con los enamorados es habitual en este tipo de textos, en donde la flor pisoteada de los caminos es igualada directamente a la situación de los amantes:

\section{Las flores de los caminos las pisan los caminantes. Yo nací para ser tuya y tú para ser mi amante.}

El humor y la música llenan de gracia y alegría las coplas canarias, sin olvidar el fuerte componente religioso de muchas de estas composiciones:
Por cantar una malagueña y en la puerta de una ermita, me dieron cuatro pesetas y un vaso de agua bendita.
Una isa ${ }^{8}$ bien cantada vale doscientos millones. Levanta los pies del suelo y alegra los corazones.

Esta última copla la enseñó Socorrito a un señor de La Palma que cantaba punto cubano para pedir dinero, y a un inválido en Gran Canaria que también pedía dinero.

Hasta la ternura puede ser un tema principal, como ocurre en la vinculación entre el amor de una madre y el de una amante:

El cariño de una madre y el amor de una mujer es el cariño más grande que en el mundo puede haber.

La alegría y las actividades cotidianas como lavar y tender se mezclan con los elementos de la naturaleza: barranco, romero, pajaritos y agua de una acequia a través de la imagen del agua que corre como símbolo de la vida, la juventud y del momento del amor:

En el barranco lavando

\footnotetext{
7 'Piedra plana'.

${ }^{8}$ Canción canaria por antonomasia.
} 
y en el romero tendiendo, los pajaritos cantando y el agua siempre corriendo.

La flor simboliza la belleza femenina en la lírica tradicional, en este copla en forma de diálogo amoroso:

-Eres como la amapola que solo en el campo nace.

-Yo nací para ser tuya

y tú para ser mi amante.

La cumbre es un motivo recurrente en la lírica tradicional canaria que, al igual que el monte, es el lugar del encuentro amoroso de los amantes en claro paralelismo con la fuente fría en la lírica tradicional hispánica. La mención de un elemento muy característico de la flora de monte en Canarias, el helecho, en su versión dialectal con género femenino, nos remite también al elemento erótico del encuentro amoroso a la intemperie de la noche a través de la voz de la joven:

En los filos de la cumbre

tengo a mi amante escondido, debajo de unas helechas ${ }^{9}$, al sereno y al rocío.

La siguiente composición habla de una de las destrezas de la amada, su habilidad para bailar, en relación a un elemento de la naturaleza como es el cielo, lo más alto en cuanto a la visión religiosa de los creyentes:

¡Válgame Dios de los Cielos, qué bien baila esta mocita!, que con la punta del pie va haciendo caracolitas.

En juego de palabras, en forma de anadiplosis en los dos versos finales, se trueca la siguiente copla a partir del nombre del amante en donde la voz femenina también se hace presente:

Antonio sé que te llamas

si no te has cambiado de nombre,

y yo llamo por Antonio

y Antonio no me responde.

El nombre podía cambiar en estos textos:

Juanillo sé que te llamas,

si no te has cambiado de nombre,

y yo llamo por Juanito

y Juanito no me responde.

\footnotetext{
9 'Helechos'.
} 
La poca importancia que uno de los amantes le concede al regalo del otro y a la posterior pérdida de este al lavar en un barranco, elementos cotidianos del quehacer doméstico, es desarrollado por medio de la graciosa metamorfosis del anillo en pez que nada por el mar:

El anillo que tú me diste

en el barranco lavando,

el agua se lo llevó

y en el mar estará nadando.

La flora, sobre todo los árboles frutales y las propias frutas, junto con las flores, también son elementos propios de la analogía entre la naturaleza y la relación amorosa en esta composición que dice María del Socorro que está destinada para cantar el marido o el novio a su mujer o amada:

¡Qué importa que el duraznero

eche una flor encarnada!

¿Qué importa que tú me quieras

si yo no te quiero nada!

La recitación y el canto en porfía era muy característico en Canarias, como ocurría con los Aires de Lima, composiciones que en muchas ocasiones se formalizaban por medio de coplas, en donde el hombre y la mujer se enfrentaban en retos poéticos con el fin de quién decía la composición más elocuente, graciosa, atinada o picante. Estas porfías o controversias también podían ser entre hombres con hombres y mujeres con mujeres. Pero, seguramente, las más divertidas eran las que se enfrentaban el hombre y la mujer, la visión varonil frente a su visión complementaria: la voz masculina ante la femenina. Estos retos podían ser muy punzantes y dolorosos, pero casi siempre eran divertidos y hacían reír a los presentes en los momentos de ocio y en las tareas cotidianas. Se dice que estas controversias entre hombres y mujeres crearon muchos matrimonios, pero también encendieron el odio entre las personas y separaron noviazgos. Como en el caso de la copla que canta Socorrito, sobre la falsa amenaza que le hace el amante a la amada de avisar a su madre de que su hija está enamorada de la Guardia Civil, de forma metonímica en relación al amante que ejerce esa profesión:

A tu madre, mi niña, se lo voy a decir que te estás enamorando de la Guardia Civil.

Estos cantares picantes, como los llamaba el padre de María del Socorro, tratan temas muy callejeros como el siguiente:

Si quieres cantar cantares

a la porfía conmigo, amárrate los calzones por debajo del ombligo.

Esto se lo decían los chiquillos a las chiquillas, y se llamaban «cantares a la porfía, que eran muy picantes», como nos dice nuestra transmisora. 
Pero la temática puede llegar a ser muy profunda y trágica, a través de un pensamiento pesimista de la existencia:

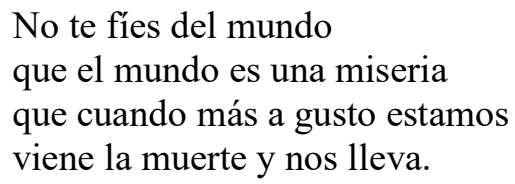

La creación poética era muy habitual entre quienes utilizaban estas coplas, como la composición siguiente en donde el poeta popular se burla de lo abrupto de la ubicación donde se encuentra la población de Artenara:

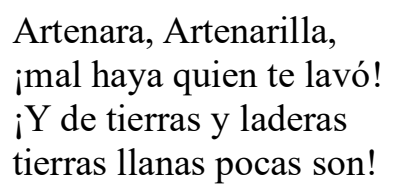

Otra forma de cantar las coplas es la siguiente:

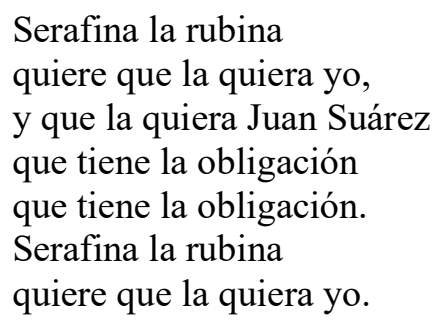

Nos dice María del Socorro que «se la cantemos a una viejita, que decía. Ahí vienen las de Loma Abajo tocando con una caña un cacharrillo. Nunca más dijo lo de que ahí viene las de Loma Abajo. La vieja se aburrió». Por tanto, la copla fue creada por ellas, la transmisora y sus acompañantes, y era cantada con el objeto de burlarse de la anciana que tan mal las trataba cuando pasaba delante de su vivienda.

El novio de María del Socorro le cantó a una chica lo siguiente:

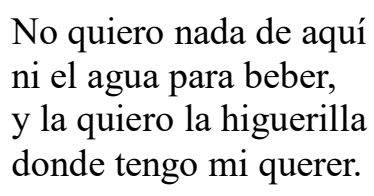

En forma de porfía, recurriendo a la metáfora del clavel como representación del objeto amoroso y de la pasión a través del símbolo cromático de «morado»o «encarnado», se cantó la copla siguiente en donde el hombre se ríe de la mujer a la que dirige el poema diciéndole que no la ama a ella sino a otra mujer mejor:

Te piensas, clavel morado, que por ti me desatino.

Tengo mis ojitos puestos

en otro clavel más fino.

Más fino sí lo será, 
pero más bonito no.

¿Te acuerdas cuándo me hablaste

y yo te dije que no?

«Lo dijo la jembra al varón» nos dice Socorrito. Y nos lo canta así:

Te piensas, clavel encarnado, que por ti me desatino.

Ten piensas, clavel encarnado, que por ti me desatino.

Tengo mis ojitos puestos

en otro clavel más fino.

Más fino sí lo será, pero más bonito no.

¿Te acuerdas cuándo me hablaste y yo te dije que no?

Un novio le dedicó a María del Socorro, desde el almacén o frente a su casa, cantares de amores como el que sigue en torno a un elemento muy reiterado en la descripción de la belleza femenina de la poesía universal como es el peinado:

Cuando María Socorro se peina

con su peinado en la moda,

así te digo Socorro

que te invito a la boda.

«Él cantaba y repetía y repetía... (lo mismo)», dice Socorrito.

María sé que te llamas

si no te has cambiado de nombre

y yo llamo por María

y María no me responder ${ }^{10}$.

La presencia de la naturaleza en correlación con la religión es habitual, como en el caso de las flores de mayo y de la Virgen María:

Las flores de mayo

se van a caer,

la Virgen María

las va a recoger.

Muy interesante es la composición que sigue, en donde la voz femenina de la copla se lamenta de la ausencia del amado por la interrupción de una mujer o de un amigo que retarda la llegada del objeto de su desesperación:

Son las ocho de la noche, son, y mi lindo amor no viene.

\footnotetext{
${ }^{10}$ Similar a las anteriores, esta vez María en vez de Antonio y Juanillo.
} 
¿Cuála ${ }^{11}$ será la traidora

o el traidor que lo entretiene?

Sobre esta composición nos dice María del Socorro que «en eso entraba el novio y se quedó con la boca abierta». Además, el primer verso está estructurado en forma de epanadiplosis, con la repetición al comienzo y al final de la oración del verbo conjugado «son» muy propio del habla popular canaria. La voz femenina representada en este poema recuerda, en palabras de Margit Frenk, «al género más característico de la primitiva lírica europea en lengua vulgar: la canción femenina» (1983: 13), como las jarchas mozárabes, la Frauendlied germana, la chanson de femme francesa, la cantiga d'amigo galaicoportuguesa, el cantar de doncella castellano y catalán, las albadas y alboradas, etc. en donde se muestran, como uno de los temas principales, la ansiedad de la amada ante la ausencia del amado. Esta temática concreta de la retardadora, en este caso traidora, que detiene al amante y no llega a la cita con la amada, que se desespera ante su tardanza, está ampliamente estudiado en el artículo de José Manuel Pedrosa «'La media noche es pasada, / y no viene': avatares de una canción, entre La Celestina y Alejo Carpentier» (2014).

La repetición del antropónimo, junto con su carga semántica como nombre común, produce una curiosa analogía entre sentir dolor en el cuerpo y el nombre de la enamorada en un doble juego entre tener molestias y tener a la amada muy presente en su cuerpo, en su voz y en su mente:

Dolores tengo en los pies,

dolores en la garganta,

si me fijo por dolores,

tú, Dolores, vas y me matas.

El juego lingüístico establece ahora una relación entre los dedos, las cuerdas y los corazones enlazados por esos dedos que muestran su amor en forma de cuerdas que atan a la amada:

Fuertes delicados dedos

que sobre las cuerdas pones.

No son dedos, que son lazos

que lazan los corazones.

El motivo del lazo es muy utilizado en la lírica tradicional hispánica como símbolo de la pérdida de la virginidad, la entrega amorosa y el anhelo del encuentro amoroso con el amante.

Muy relacionada con la vida de los habitantes del sureste de Gran Canaria es la copla que habla sobre su ocupación laboral principal, la zafra del tomate, en forma de relación entre el cultivo, la enfermedad del mismo y el amor:

La semilla del tomatero se la comieron ${ }^{12}$ la legarta ${ }^{13}$, por eso yo no quiero amores de zafra.

\footnotetext{
11 'Cuál'.

12 'Comió'.

13 'Legarto: enfermedad de los tomateros a causa de la larva de un insecto'.
} 
Algunos cantares han sido creados por personas que María del Socorro ha conocido, como los de Juan Cruz:

Eres mi prima,

prima que a mí no me pesa:

¿quién no te pudiera llevar

de mano para la iglesia?

Prima, que eres mi prima,

prima, ¡qué bien te quiero!:

¿quién te pudiera llevar

como el anillo en el dedo?

Esta noche va de rumba

las alas de mi sombrero:

quien quiere salir que salga,

que en el camino lo espero.

El primer y segundo texto hablan de la amada, prima suya, a la que le confiesa su deseo de llevarla al altar en matrimonio. El tercero, muy divertido, personifica a su sombrero que quiere salir de fiesta e invita a quien quiera que le siga. a ella:

Otro autor conocido de las coplas fue el marido de María del Socorro, que le cantó

Tengo una novia en La Higuerilla

que la quiero más que a naide.

¡Vaya las novias que tengo

que se vayan a la calle!

Otra composición que habla de la música es la siguiente:

No canto por bien que canto

ni porque lo pienso hacer,

canto porque me mandaron:

me gusta poder ser.

Las plagas son uno de los males que azotan de forma cíclica los campos isleños, que asolan los cultivos y dejan a las familias en ruinas porque se lo comen todo. La vinculación entre cigarrón, símbolo de la destrucción de los cultivos, y la amada es clara:

El cigarrón beberisco ${ }^{14}$

tiene un letrero en las alas,

diciendo que no lo mate,

que es castigo que Dios manda.

Y lo canta también de la siguiente manera:

El cigarrón en beberisco

14 'Berberisco'. 
tiene un letrero en las alas.

El cigarrón en beberisco

tiene un letrero en las alas,

diciendo que no lo mate,

que el castigo que Dios manda,

que el castigo que Dios manda

tiene un letrero en las alas.

La alegoría siguiente aúna el campo semántico de las aves (perdiz, pico, grano, captura del ave) con el del matrimonio con la amada. La perdiz, por tanto, es la imagen irreal de la metáfora con la amada, a través del símil inicial:

Eres como la perdiz

con el pico coge el grano,

ansina te cojo yo

en la iglesia con la mano.

Y lo canta siguiendo esta estructura paralelística:

Eres como la perdiz

con el pico coge el grano.

Eres como la perdiz

con el pico coge el grano,

ansina te cojo yo

en la iglesia con la mano,

en la iglesia con la mano.

Sobre este último texto nos dice María del Socorro que «me lo escribió a mí mi novio»».

Como si de un juicio real se tratara, es cantada esta copla en donde el litigio consiste en dilucidar si el amor es delito y ha de ser condenado con la pena de muerte:

Hasta los cielos subí

a preguntarle al fiscal

que si el querer es delito,

que me manden a matar.

Nos dice Socorrito que «eso lo cantaba todo el mundo por ahí. Si tienes una novia, y no te quiere, que te manden a matar».

Las coplas siguientes atienden a una circunstancia sufrida por los canarios en el siglo XIX y principios del siglo XX, la tragedia de la emigración a causa de las penurias económicas reinantes en ese periodo. La presencia de La Habana en muchas composiciones tradicionales canarias, y la llegada del punto cubano, son notorias en textos como estos basados en estructuras palalelísticas:

De La Habana vine aquí

navegando en un tacor $^{15}$,

para yo venirte a ver:

jociquillo de ratón.

15 'Vapor'. 
De La Habana viene aquí navegando en un zapato, para yo venirte a ver, jociquillo de legarto ${ }^{16}$.

De Cuba para La Habana vi a Ana Ortega, en una fresca mañana, en tiempo de primavera.

De La Habana vine aquí metido en un gallinero; las malditas gallinas me cagaron el sombrero.

La descripción de la amada se manifiesta a través del símil constante en la comparación de su belleza con la blancura de la leche, el rojo del vino y los ojos del color del manto verde de la Virgen del Pino de Teror, patrona de Gran Canaria:

Eres blanquita como la leche y encarnada como el vino, tienes tus ojitos verdes como la Virgen del Pino.

Y nos dice que «esto se cantaba cuando se iba a Teror», de romería. El motivo de la belleza femenina en su plasmación en la tez blanca, el rubor encarnado y los ojos verdes es reiterativo en la poética clásica, renacentista, barroca y neoclásica. De hecho, el poema recuerda al soneto XXIII de Garcilaso.

Las dos coplas siguientes habla del Roque Montaiga, en vez de su término actual de Bentaiga, ¿será el verdadero nombre aborigen del monte como ocurre con la confusión entre Roque Nubro con Nublo que postulan algunos autores? Los cariños, nos dice María del Socorro, son los postres típicos de la zona alta de Gran Canaria caracterizada por la preparación de un gran surtido de dulces hechos con almendras:
Y debajo del Montaiga
hay unas almendras blancas
para llevarlas a Tejeda
para el cariño de Santa.
Debajo del Montaiga
hay unas almendritas dulces
para llevarlas a la casa de Luisita
para poder hacer un dulce.

La representación del amor platónico, profundo, que llega hasta los «rincones del alma», aparece representado en esta composición:

Te piensas que no te quiero

\footnotetext{
16 'Lagarto'.
} 
que mi querer na desmanda.

Te quiero porque me sale

de los rincones del alma. universal:

El color de los ojos también refleja el amor, tema muy recurrente en la poesía

Todos los ojitos negros

los van a matar el lunes;

no tengas penas de los míos

que los míos son azules.

Al pasar por cementerio, y es que me da mucha pena, porque allí tengo enterrados

los ojos de mi morena.

Más picantes son los cantares que les hacían los chicos a las chiquillas:

Eres chica redondita

como el rabo de la tórtola;

lo que tienes de chica,

lo tienes de calentona.

Eres chica redondita

como pipa de limón;

entre más grande y más chica

ansina te quiero yo.

Una copla muy popular en Canarias, recogida en muchos cancioneros y cantada como isa, es la siguiente:

Pobrecilla de mi madre

que en el mundo tuvo quince:

todos fueron guitarras,

no siendo yo que fui timple.

La diferencia de la guitarra, que es más melódica, dulce y suave, con el timple es que este es más impulsivo, chillón y animado; es decir, mis hermanos salieron tranquilos y equilibrados y yo salí vivaracho e impulsivo. Se trata de dos instrumentos de acompañamiento en las agrupaciones folclóricas, pero mientras que puede haber muchas guitarras tan solo hay uno o dos timples porque estos últimos sobresalen más sobre el conjunto.

La alusión a dos motivos bíblicos como el Paraíso Terrenal, en donde Adán y Eva transgredieron la norma de no comer de la manzana prohibida con la consiguiente expulsión de este lugar idílico, y la Gloria, que según el Diccionario de la Lengua Española significa «estado de felicidad plena e inefable en presencia de Dios y en comunión con los demás bienaventurados, después de la muerte» (DRAE) entre los cristianos, ensalza hiperbólicamente la magnificencia del paisaje de la Cruz de Tejeda: 
Las puertas del Paraíso

las puso Dios en nuestra tierra

el que quiera ver la Gloria

vaya a la Cruz de Tejeda.

Esta copla ha sido recogida por Maximiano Trapero (1990b: 159).

El combate de dos cuervos se centra, de forma irónica, en disputarse las orejas del novio, lo que significa que alguien, posiblemente la emisora del texto, está hablando mal de él:
Allá enfrente en aquel lomo hay dos cuervos peliando ${ }^{17}$, las orejas de mi novio se las están aspirrafando ${ }^{18}$.

En palabras de Socorrito, «la hembra se lo decía al chiquillo», al novio:

Mira que te lo tengo dicho, no te lo dejo decir, que te quites de la puerta cuando me veas venir.

La siguiente copla la cantaba la tía de María del Socorro, y dice que fue inventado y cantado para una mujer hermosa que se casó con un viudo, en un bello paralelismo entre la higuera y sus diminutos e inútiles frutos y la mujer hermosa casada con un hombre mayor con el que no puede llegar a la plenitud del amor, en clara alusión sexual:

¡Maldita la higuerilla que echa los higos menudos! ¡Maldita la mujer hermosa que se casa con un viudo!

Los elementos de la naturaleza se unen para ponderar la belleza de los ojos de la amada en la cuarteta siguiente:

Cuando la aurora tiende su manto, el cielo santo viste de azul, y no hay lucero que alumbre tanto como los ojos que tienes tú.

El juego verbal entre las palabras ola y sola y divertir, a través de la figura literaria de la derivación, se refleja en la siguiente copla:

Las olas del mar son solas, ellas solas se divierten, y yo me divierto donde me he divertido siempre.

\footnotetext{
17 'Peleando'.

18 'Rompiendo'.
} 
En forma de adivinanza, cuya solución es que «los padres eran hermanos», se configura la copla siguiente:

Si quiere saber, señores, qué parentesco nos damos.

Semos hijos de padre

y de primos hermanos.

Finalizamos el amplísimo repertorio memorístico de coplas de María del Socorro con dos coplas cantadas:

La luna y el sol pelearon por un cochafischo ${ }^{19}$ millo. La luna y el sol pelearon por un cochafischo de millo.

La luna se quita un diente el sol se quita el colmillo, el sol se quita el colmillo por un cochafisco millo.

A mí me llaman, me llaman, sereno y sereno mucho vale.

Anoche dormí contigo $\mathrm{y}$ tu madre no lo sabe. Anoche dormí contigo $\mathrm{y}$ tu madre no lo sabe A mí me llaman sereno y sereno mucho vale.

Aparte de las coplas, encontramos otro tipo de cantares tradicionales en el repertorio de María del Socorro. Uno de los temas por excelencia de las parrandas en Canarias, cuyo autor fue el compositor, escritor, historiador y periodista Néstor Álamo Hernández, la cantó María del Socorro en mi honor, como podrá comprender el lector:

Andrés, Andrés, repásate el motor que se te sale el agua por el carburador. Andrés, Andrés, repásate el motor que se te sale el agua por el carburador. ¡Ay, qué noche tan escura! ¡Ay, qué oscuridad tan grande! ¡Ay, qué niña más bonita si me la diera su madre, si me la diera su madre! ¡Qué oscuridad tan grande! ¡Ay, qué noche tan oscura y que oscuridad tan grande! Andrés, Andrés, repásate el motor que se te sale el agua por el carburador.

19 'Maíz tostado'. 
De creación local es el texto transcrito a continuación creado con motivo de un hombre, al que le hicieron este cantar, llamado Domingo que tenía la novia en Acusa, y como «la gente es la gente, le pusieron un nombre a Domingo. Y él se quedaba rabiando cuando le decían eso» cuando le cantaban esto:

Domingo Respingo,
pimpollo dorao,
las viejas de Acusa
te tienen engañao
por un polvo de gofio
y un hueso de pescao.

De carácter humorístico es la canción sobre la Ramona:

La Ramona tiene un pelo.

Pelona, sin pelo.

Los tres pelos que tenía

los llevaba a trapelo.

Ramona, Ramona.

La pelona no tiene pelo,

los tres pelos que tenía

los llevaba a trapelo

Pelona, sin pelo.

La pelona está rascada porque no le crece el pelo.

Los tres pelos que tenía los llevaba a traspelo.

Pelona, sin pelo.

Los tres pelos que tenía

los llevaba a traspelo...

Nos dice María del Socorro que su madre era costurera, y como no le gustaba el sentido del siguiente terceto, se «enroñaba» cuando lo cantaban diciendo «como ustedes digan ese cantar, les parto la cara, porque eso no se puede decir» debido a la incitación sexual que emana la expresión «tú me lo darás»:

\section{Costurera, costurera \\ tú me lo darás \\ cuando quieras.}

En cuanto a los Ranchos de Ánimas, grupos de personas que cantan en invierno por las calles a las ánimas del Purgatorio (Trapero, 2011: 437-572) con la finalidad petitoria de elevarlas al Cielo (actualmente quedan muy pocos Ranchos de Ánimas en Canarias: Teror, Valsequillo y La Aldea de San Nicolás en Gran Canaria; Tiscamanita en Fuerteventua, etc.), los oyó nombrar pero no los recuerda puesto que solo aprendieron lo que los padres les enseñaron. Sí que los había en Tejeda, pero quedaba lejos, vivían a hora y media caminando y estos ranchos nunca llegaban hasta La Higuerilla. 


\section{REZADOS Y SANTIGUADOS}

Los rezados y santiguados son muy comunes en Canarias, por motivos muy diversos se utiliza la oración religiosa popular con la intención de obtener de Dios, la Virgen o los santos el provecho, la protección o la salud. En el poema que nos sigue, la emisora del texto solicita a san Antonio que le conceda el deseo del matrimonio, puesto que este santo es muy conocido como propiciador de las relaciones amorosas, en especial, las del matrimonio:
A san Antonio bendito
le tengo ofrecido un lazo.
A san Antonio bendito
le tengo ofrecido un lazo
con metro y media ${ }^{20}$ de cinta
a ver si este año me caso.

En el rezado siguiente se le ofrece, a quien canta la copla, una ermita a san Juan en el Cielo si le concede su deseo:
San Juan bendito en el Cielo
no tiene ermita ninguna;
dentro de mi corazón
le voy a fabricar una.

\section{CUENTOS, CHISTES, ABERRUNTOS Y FRASEOLOGÍA}

Uno de los primeros cuentos que nos ofrece la memoria de nuestra transmisora es el siguiente texto, que no deja de tener también su rasgo lírico, humorístico y bien podría catalogarse como chiste:

Ay, mundo, mundo

que te va llevando uno a uno:

que no te diga zape.

Una que tenía una sardina, y se murió un señor, y la vieja en vez de llorar lo decía al gato.

Historias de borrachos hay miles, en este caso tenemos una en forma alegórica de un ratón y un gato que se deja engañar por su presa:

\section{La historia del ratón en la botella}

Dice que había una botella de vino, y el ratón estaba en la botella. Y el ratón le dijo al gato:

- Si me sacas de aquí, cuando me seque, te dejo comer.

-Sí, sí.

El gato tanto anduvo que sacó al ratón. Pues, ¿qué hizo él? El ratón se puso al sol, se sacudió. Ras. Y el ratón, cuando el gato se dio cuenta, se perdió y no se dejó comer. Y entonces le dice el gato al ratón:

_ ¿Pero tú no dijiste que cuando te secaras te dejabas comer?

Y le dijo el ratón:

— ¿Y quién cree a un borracho?

20 'Medio'. 
Bajo el formato de canción dramatizada en verso también tenemos el siguiente cuento de nunca acabar:

Las palomas del rey se bebieron el agua.

Dice que no anda

— ¿Por donde anda?

-Por el agua.

Otro cuento proporcionado por María del Socorro es el siguiente:

Dice que Dios le dijo al mar que [eligiera entre] si el mar crecía el tamaño del negro de una uña o tragarse una persona cada día, y digo yo que prefiero que se trague cada día a una persona a que crezca lo negro de una uña cada día porque ya todo sería agua. Mi padre me contó este cuento. Mi padre sentao con nosotros. No sabía ni leer ni escribir.

Sobre un engaño realizado por los de Tejeda a los de Las Palmas, nos cuenta Socorrito el siguiente relato, en donde se menciona los posibles nombres originarios del Roque Nublo y del Roque Bentaiga:

Fue un matrimonio de Tejeda para abajo a Las Palmas a comprar, y como no tenían dinero para pagar, les preguntó:

— ¿Cómo se llama usted?

-Yo Roque Nubro.

Y su mujer:

- María Montaiga.

Y dicen que fueron a Tejeda a preguntar por este matrimonio. Y le respondieron que aquel es el Roque Nublo y el otro el Roque Mentaiga. Creo que fue verdad. padre:

El chiste siguiente es el único que recuerda de pequeña, que se lo contaba a su

- ¿Qué le dice un sombrero al otro?

- Vamos en cabeza

Un aberrunto típico de la zona sureste de Gran Canaria que vaticina la llegada o existencia de viento fuerte, muy habitual en esta zona de la isla, nos lo cuenta Teresa:

Cuando se asoma aquella barra que está allá ha habido viento (y señala hacia Arinaga desde su vivienda en Casa Pastores).

María del Socorro nos cuenta otro propio de La Higuerilla:

Estamos sembrado la sementera, mi padre hacía un montón de sementera, y sonaba un tiempo chiquitito ${ }^{21}$ allá lejos. Y se pone mi padre:

-Chiquillos, chiquillos.

Veía el tiempo asomar, por allá abajo, por el pinar.

-Chiquillos, chiquillos, recojan, recojan, que va a llover.

\footnotetext{
21 'Pequeña tormenta'.
} 
En un momento se formó unos chamusquines de agua ${ }^{22}$, se puso un tiempo... en el Pinar de Acusa. De Tamadaba pa arriba. En la Higuerilla.

Un ejemplo de fraseología canaria es el siguiente:

Apenas conozco la cuchara del gofio para comer.

\section{LEYENDAS: HISTORIAS DE BRUJAS, DIABLOS, PERROS DE FUEGO, APARECIDOS Y LUCES}

Los cuentos de brujas, diablos, aparecidos, perros de fuego y luces, verdaderas leyendas tradicionales en donde las creencias populares entran en conflicto con la ciencia y la tecnología actual, son muy habituales entre la gente que vivía en los pequeños pueblos del centro de la isla. La oscuridad de la noche, el temor a lo desconocido, la búsqueda de una explicación a los fenómenos que no comprendían, han creado en Canarias un innumerable catálogo de leyendas como las que sigue:

Dice que antes había brujas, mi padre era uno que día ${ }^{23}$ por un camino, que hicieron un tal Matías, y mi padre iba con dos bestias, cargado de carbón para dí ${ }^{24}$ a San Mateo, y nosotros vivíamos al pie de la montaña pa bajo. Y mi padre, por lo visto, día por el camino y les descargaba los burros, mi padre los cargaba y se los descargaba, los amarraba y se los desamarraban, y también le pasó a mi padre, y a mis tíos también.

Y también vi a mi padre una vez, por ese sitio más pacá, más pacá, y había una verea y había una señora en la verea, y dice que le dijo a mi padre. Mi padre le dijo:

-Adiós.

Y la señora dice:

-Adiós.

- ¿Tú has visto llegar a mi hijo por la verea?

-No, su hijo está al llegar.

- Mi padre siguió su rumbo, y cuando estaba más pallá, pallá, dice que miró y no había naide. Vestía canelo, con un pañuelo y un delantal. Mi padre dice que no vio nunca más ni el que venía atrás ni el que venía alante.

Y después había otro cuento, que era un tío de mi madre, fue a la junta ${ }^{25}$, de la casa donde vivía mi gente para arriba, otro barrio. Salió un hombre de las juntas a la casa y mi tío ese sabía un rezado muy bonito y dice que salió un hombre de pacá, pacá y había como un charco grande de tierra, no había agua ni nada, y un hombre con una pata de palo le cayó atrás, llegó cerca de la casa de mi abuela pabajo que era un cacho y se ponía:

_ iQue te lo quito! ¿Que te lo quito! ¿Que te lo quito!

Y llegó allá abajo y el hombre desapareció, hizo el rezao y nunca más lo vio.

Y también mi padre tenía una novia y fue a La Solana, de La Solana a mi casa hay un cacho, y dice mi padre cuando venía en el camino un olor a manzanas que partía el alma y cuando llegó a la casa, se tiró mano al bolsillo y llevaba tres manzanas y llamó a la madre. Mamá, y mi abuela... que pusiera las manzanas arriba

\footnotetext{
22 'Lluvia fuerte'.

23 'Iba'.

24 'Ir'.

25 'Reunión de gente para coger almendras, descamisar millo, o realizar cualquier tarea colectiva'.
} 
de la cómoda, y las puso mi padre arriba de la cómoda, mañana estarán todas llenas de bicho negro. Eso sí lo sé yo. To llena de bicho negro. Y él siempre se lo pegó a una novia que tenía (que era bruja). Así te digo que hay de tó.

«Y con Dios todo, y sin Dios nada». Decía el padre de Socorrito siempre. «Dios por delante de todo».

Y, como agrega Socorrito: «había muchas cosas más, a uno le pasaba esto, a otro otra cosa». Porque las brujas eran personas normales que volaban en escobas y que se llevaban a los niños recién nacidos, pero no sabe mucho más sobre ellas. Las brujas hacían cosas malas pero también buenas. Eran creencias, nos dice Socorrito, porque «antes no había luz, (sino) luces de pretóleo y tú días a buscar agua con eso».

Una vez diendo ${ }^{26}$ pa Tejeda, que eso es un camino muy grande, que le decían La Zarzita, que cogieron una niña en La Solana y la pusieron en La Zarzita. Y la gente buscando a la niña, y no sé quien pasó, y vio a la niña en la zarza. Antes sí se veían cosas, ahora no, y no digo que todo fuera mentira.

A mi suegro lo cogían y lo tiraban pacá y pallá, y entoavía era viejo, tenía 90 años o más y era mayor el hombre iría parriba y siempre decían que venían las brujas allá arriba. Mi marío decía el cuento que su padre volaba de un lao a otro. Y ordeñar las cabras, las brujas, ordeñar las cabras un montón de leche y dispués mañana estaban las cabras igual llenas de leche.

Antes había una señora que tenía sus hijas, una hija se casó con un señor de Las Palmas. El señor de Las Palmas le daba mala vida, tenía dos niñas. Y, ¿qué hizo ella?, se fue con la madre y sus niñas, y el hombre la iba a buscar, y ¿qué hacía la madre de ella?: escondía a la hija para que el marío no se la llevara porque le pegaba. En montón de sitios, en rajones ${ }^{27}$ grandes y las metía allí y les daba comida y agua y muchas veces las escondía en las barricas. Y el hombre venía y no las encontraba y por aquí y por allá. Escondió a esa mujer muchos años. Pues dice que una vez cuando llegó de vueltas y cuando llegó a un barranquillo que no había nadie dice que venía un perro con unas cadenas a rastro echando fuego por el jocico y dice que la madre:

-Vámonos mi hija, pa la casa y vete con tu marío.

Yo no te escondo más. No sabía si era bruja o era el diablo. Siempre desde niña yo lo oía, el diablo se mete mucho en el matrimonio. Tú estás picao contigo y yo conmigo.

Dice que una vez había dos hijos, y el padre estaba malito, y un hijo se puso a tocar la guitarra y el otro hijo se puso a ver a su padre, estaba malito. Y se murió el hombre. Y salió otro hombre y le dice:

- ¡Maldito! Que por cuenta de tus cuerdas me has quitado el alma de tu padre.

Porque cuando mueres el enemigo y Dios están peliando a ver quién se lo lleva. Porque si dices cosas malas tienes que pagarlo. Porque el enemigo, el diablo, es amigo de las guitarras, de las cuerdas.

Una hermana mía tenía un niño grandito y mi madre a todos me mandó a estar con mi hermana a cuidar al niño y darle de comer, a niños grandes, y me acuerdo que mi hermana vivía en una cueva tan bonita y tenía una cocina, en un rincón

\footnotetext{
26 'Yendo'.

27 'Cajones'.
} 
hacía la comía. Se murió la señora y mi hermana se pasó a la cocina de la señora. Y mi hermana me mandó a calentar la leche en la cocina, yo era chica. Y cuando yo llegué a la puerta, y tenía las cosas de la cocina allí. Y había una mujer sentá ${ }^{28}$ con unas medias negras y unas flores amarillas envueltas como una sábana y yo como era chica di gritos y a llorar, y mi hermana me oyó. Yo siempre he dicho que era la mujer que se murió. Se había muerto la mujer hacía poquito. Antes cómo vivía la gente, mi hijo, con poquito, y nos remediábamos con lo que teníamos.

Mi padre se fue pa Artenara y pasó por Acusa. Y mi padre tenía una novia que era tía de mi marido, y estaba la madre de la novia de mi padre arriba en un risco dice que pegó a la piedra limpia con mi padre: bandío.

-No te casaste con mi hija, pero tengo cuatro hijos que son cuatros primores,

Mi padre, las carreras por el barranco porque la vieja le cayó atrás. La vieja no era bruja, sino era mala. A lo mejor era bruja, qué sé yo. Fue cerca de un molino, cerca de Artenara, Dice:

- Tengo cuatro yernos como cuatro primores.

Dice mi padre:

-Pues, cómaselos.

Y una prima mía que se murió allí y el marío fue a hablar con una señora que hablaba con los difuntos, Zaragoza, que era de Lugarejos, y fue y le dijo:

- Que fuera a pagarle una promesa a la Virgen del Pino que le había ofrecido.

Y a los hijos... de cosas de brujas que tenía para que se la diera. Y estaba mi prima penando, de verdad. Fue y le mandó aquella a decirle que le había dicho que le mandó descansar. Y de vueltas ella vino y le dio las gracias. No sé si será verdad o mentira, pero algo hay.

Nos dice Socorrito que estas historias, que la gente creía como reales, eran debidas a que «antes no había luz, to oscuro, antes todos los gatos eran pardo». También oyó hablar de historias de gigantes en Tirajana, pero no las recuerda.

Mi abuela decía que una noche él oía mucho ruido, ruido, ruido y fue a donde estaban los animales y estaban las brujas allí y cogió la bruja a ella. Entonces ella amaneció por allí, y no podía salir, y las reconoció, y la [dejó] hasta mañana, y le amenazó que si la descubría le hacía algo a ella. (Contado por la hija Esther).

Oír cadenas, la luz que veía volaba. La Luz. Montón de gente la vio. Que eran las brujas, que eran las brujas, decía la gente. Se mueve. Y todavía está en la Higuerilla, que baja, que por el aire vuela parriba y pabajo. (Contado por la hija Esther).

Mi abuelo hablaba con los muertos, y en sueños decía:

— ¡Déjame ya! ¡Déjame ya! ¡Déjame ya!

Para que lo dejaran tranquilo. Dice que en esas fechas de todos los santos se ponía flaquito. (Contado por la hija Esther).

También yo he oído el cuento de que alguien iba caminando, y se quedaba en el mismo sitio caminando, y que era el mismo camino, y nunca llegaba a la casa. Y era el mismo camino. (Contado por la hija Teresa).

28 'Sentada'. 
El viejo cuando vivía en la cuartería, donde está La Ciel, él dice que no había luz, nada más que tierra y tomatero. Eso contó la gente. Y él dice que de noche vio una sombra grande y empezó a correr y la sombra sacaba polvo. Y notaba que corría detrás de él. Y corriendo, corriendo, llegó y había una puerta roja, llegó a la puerta de la cuartería y cerró la puerta. Y al día siguiente dice que la puerta estaba tirada en el suelo. Era un niño cuando eso. Que era mucha la tierra y que lo oía muy claramente que corría detrás de él. (Contado por la hija Teresa).

\section{JUEGOS EN LOS BAILES E INFANTILES}

Muy típicos son los juegos que se hacían durante los bailes, para amenizar la noche y descansar de su agotador movimiento, y se ponían en acción las siguientes actividades de entretenimiento:

A.- El juego de La gallinita ciega: «se amarraba un pañuelo [en los ojos para que no viera] y pegaban ${ }^{29}$ a correr unos detrás de otro. El que ganaba, ganaba y el que perdía, se jodía. Se cogían unos a otros». Este juego está recogido, de forma muy breve, en la obra Folklore infantil canario y otros estudios etnográficos (1991: 100) de Luis Diego Cuscoy y más ampliamente en el Folclore infantil canario (1986: 195-196) de José Pérez Vidal.

B.- El juego de Las palomas del rey. Era un juego en que uno le daba un anillo a otro, y le decía:

— ¿Cómo te llamas tú?

Uno se llamaba azúcar, café, garbanzo.

- Las palomas del rey se bebieron el agua, ¿por dónde anda?,

-El café brincaba.

El otro lo otro,... hasta que llegaba al anillo. Los pasábamos bien, en mi juventud. Y cantábamos a la porfía mucho:

—El anillo que tú me diste.... Y continúa.

Jugaban al anillo, a las palomas del rey. Éramos un grupo grande, uno era azúcar, garbanzo, judía, millo, café, y to ${ }^{30}$ mundo jugábamos:

Por garbanzo anda. Por judía anda...

Y era el anillo que andaba de mano en mano. Ya no me acuerdo.

Las niñas también jugaban en corro, «una juntá de niños»:

Al corrito san Miguel, el que se ríe va al cuartel, ijey!, pin, pan, corriendo.

«y se libraba o se agarraban unos a otros, y si cogían la piedra peldía ${ }^{31} »$.

Versiones diferentes de esta composición las encontramos en la obra Folclore infantil canario (1986: 139) de José Pérez Vidal.

Su hija Teresa recordó y cantó las siguientes canciones de corro:

\footnotetext{
29 'Empezaban'.

30 'Todo'.

31 'Perdía'.
} 


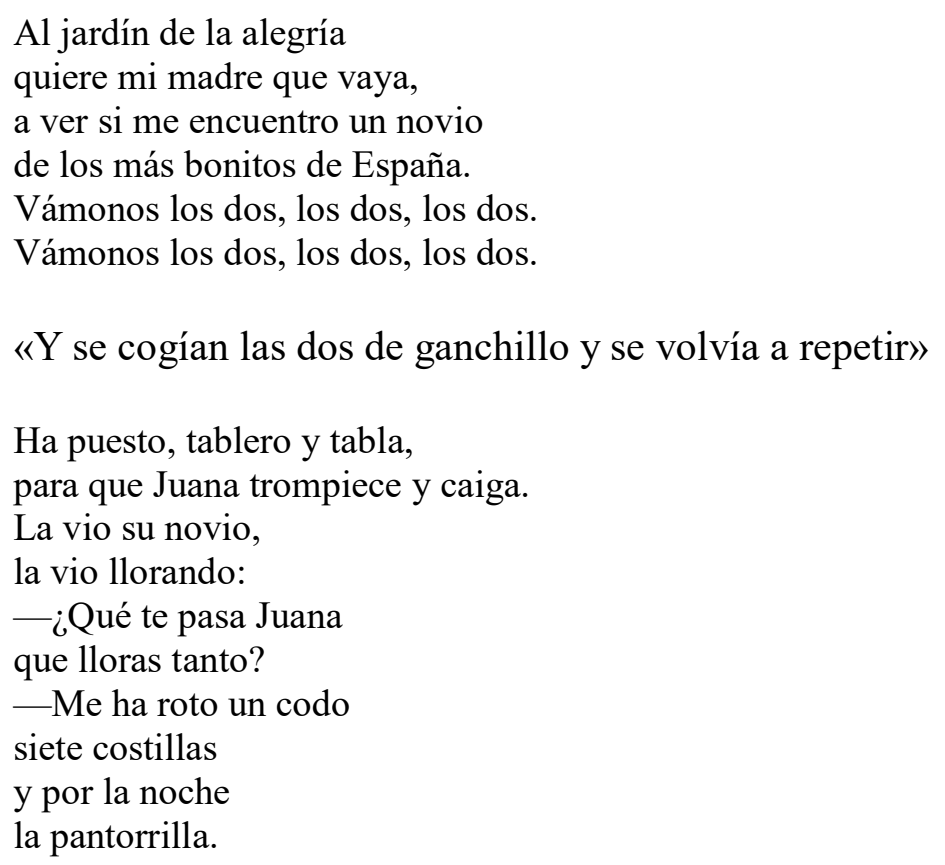

Nos dice Teresa que el nombre puede ser Juana, Lola, Pepa, etc. y que son «cantares de niñas».

\section{CONCLUSIONES}

La muestra textual recogida en este artículo, a pesar de contar con muy pocos informantes, es muy representativa de la rica vida tradicional de cantares y decires que tuvieron los grancanarios del centro de la isla: una buena selección de romances, un número muy abundante de coplas locales, cuentos e historias de brujas y juegos infantiles de corro o propios de los bailes de los adultos.

En cuanto a los romances, es una colección representativa puesto que recoge los más conocidos de la zona y demuestran que el romancero siguió vivo hasta hace pocas décadas en Gran Canaria, y que permanece aún en la memoria de las personas de más avanzada edad ya en vía de desaparición.

Por su lado, lo más sobresaliente de esta recolección son las coplas, los cuentos y las historias de brujas que reflejan fielmente cómo era la vida y las creencias populares de los canarios hasta no hace muchas décadas. Las fiestas, los bailes, las bromas que se cantaban, el trabajo en el campo en todas sus variantes, la religión, la formación de creencias en torno a lo inefable y desconocido, los juegos infantiles, etc. Una forma de vida imposible de recuperar en el desafiante mundo actual de la cultura globalizadora de los medios de comunicación de masas, que aún sigue viva en los últimos reductos del imaginario popular: los ancianos de los más recónditos medios rurales.

\section{BIBLIOGRAFÍA}

Academia Canaria de la lengua (2010): Diccionario Básico de Canarismos, La Laguna, Academia Canaria de la Lengua. [DBC]. 
Corrales Zumbado, Cristóbal, Dolores Corbella DíAz y M. ${ }^{\mathrm{a}}$ Ángeles Álvarez MARTÍNEZ: Tesoro lexicográfico del Español de Canarias, Real Academia Española, Gobierno de Canarias, Madrid, 1992, 972 pp. [TLEC].

CusCoy, Luis Diego (1991): El folklore infantil y otros estudios etnográficos, prólogo y selección de textos por Alberto Galván Tudela, Santa Cruz de Tenerife, Museo Etnográfico y Aula de Cultura de Tenerife, Cabildo Insular de Tenerife.

Fernández Del CASTILlo, Felipe Santiago (1993): Caleidoscopio de coplas palmeras, Santa Cruz de Tenerife, Centro de Cultura Popular Canaria y Cabildo Insular de La Palma.

FRENK, Margit (1983): Lírica española de tipo popular. Edad Media y Renacimiento, Madrid, Ediciones Cátedra.

Lorenzo, Antonio; MorerA, Marcial y Gonzalo OrTega (1994): Diccionario de canarismos, La Laguna, Francisco Lemus. [DC].

Lorenzo Perera, Manuel J. (1981): El folklore en la isla de El Hierro, con la colaboración de Rosa M. ${ }^{a}$ Montesinos Sirera, Santa Cruz de Tenerife, Editorial Interinsular Canaria y Excmo. Cabildo Insular de El Hierro.

MUSEO NÉSTOR ÁlAMO. URL:

http://www.museonestoralamo.com/index.php?option=com_content\&view=artic le\&id=32\&Itemid=11, 25.11.2018

NodA GóMEZ, Talio (1978): La música tradicional canaria, hoy, prólogo de Lothar Siemens Hernández, Las Palmas de Gran Canaria, Imprenta Lezcano.

NodA GómEZ, Talio (1998): La música tradicional canaria, hoy, Las Palmas de Gran Canaria, Ediciones Fundación Orquesta Filarmónica de Gran Canaria.

PedrosA, José Manuel (2014): «'La media noche es pasada, / y no viene’: avatares de una canción, entre La Celestina y Alejo Carpentier», Celestinesca, 38, 2014, pp. 85-112.

PÉREZ VidAl, José (1968): Poesía tradicional canaria, Gran Canaria, Cabildo de Gran Canaria.

PÉReZ VIDAL, José (1986): Folclore infantil canario, Madrid, Ediciones del Excmo. Cabildo Insular de Gran Canaria-ICEF.

PÉREZ VIDAL, José (1987): El romancero en la isla de La Palma, Madrid, Cabildo Insular de La Palma.

REAl ACADEMIA EsPañola (2004): Diccionario de la lengua española, Madrid, Editorial Espasa-Calpe. [DRAE].

TrAPERO, Maximiano (1982a): Romancero de Gran Canaria I (Zona del sureste: Agüimes, Ingenio, Carrizal y Arinaga), transcripción y estudio de la música de Lothar Siemens Hernández, Las Palmas de Gran Canaria, Excma. Mancomunidad de Cabildos de Las Palmas, Instituto Canario de Etnografía y Folklore.

TRAPERO, Maximiano (1990a): Romancero de Gran Canaria II, transcripción y estudio de la música de Lothar Siemens Hernández, Las Palmas de Gran Canaria, Cabildo Insular de Gran Canaria.

TrAPERO, Maximiano (1990b): Lírica Tradicional Canaria, Islas Canarias, Viceconsejería de Cultura y Deportes del Gobierno de Canarias, Biblioteca Básica Canaria.

TRAPERO, Maximiano (1991): Romancero de Fuerteventura, transcripción y estudio de la música de Lothar Siemens Hernández, Las Palmas de Gran Canaria, La Caja de Ahorros de Canarias. 
TRAPERO, Maximiano (1993d): La flor del oroval: Romances, cuentos y leyendas de San Bartolomé de Tirajana, Las Palmas de Gran Canaria, Ayuntamiento de San Bartolomé de Tirajana, Colección Pancho Guerra.

TRAPERO, Maximiano (2000a): Romancero General de La Gomera, transcripción y estudio de la música de Lothar Siemens Hernández, La Gomera, Cabildo Insular de La Gomera, 2. ${ }^{\text {a }}$ edición revisada y muy ampliada.

TRAPERO, Maximiano (2000b): Romancero General de La Palma, con la colaboración de Cecilia Hernández Hernández y transcripciones musicales de Lothar Siemens Hernández, Madrid, Cabildo Insular de La Palma.

TRAPERO, Maximiano (2003a): Romancero General de Lanzarote, Madrid, Fundación César Manrique.

TRAPERO, Maximiano (ed.) (2003b): El romancero de La Gomera y el romancero general a comienzos del tercer milenio. Actas del Coloquio Internacional sobre el Romancero, celebrado en la isla de La Gomera (Islas Canarias), del 20 al 24 de julio de 2001, Tenerife, Cabildo Insular de La Gomera.

TRAPERO, Maximiano (2006): Romancero general de la isla de El Hierro, con un estudio de la música de Lothar Siemens Hernández, Madrid, Cabildo Insular de El Hierro, segunda edición corregida y muy aumentada.

TRAPERO, Maximiano (2011): Religiosidad popular en verso. Últimas manifestaciones o manifestaciones perdidas en España e Hispanoamérica, México, Frente de Afirmación Hispanista, A.C.

Fecha de recepción: 27 de noviembre de 2018

Fecha de aceptación: 2 de marzo de 2019

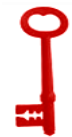

